\title{
Effectiveness of Krisoker Janala in Disseminating Agricultural Information: An Innovative Tool
}

\author{
Mst. Sharmin Sultana*, Md. Sekender Ali, Md. Rafiquel Islam, Muhammad Humayun Kabir, \\ Md. Kanob Hasnat \\ Department of Agricultural Extension and Information System, Sher-e-Bangla Agricultural University, Dhaka, Bangladesh \\ Email: *mhumayunsau@gmail.com
}

How to cite this paper: Sultana, M.S., Ali, Md.S., Islam, Md.R., Kabir, M.H. and Hasnat, Md.K. (2019) Effectiveness of Krisoker Janala in Disseminating Agricultural Information: An Innovative Tool. Open Journal of Social Sciences, 7, 272-280. https://doi.org/10.4236/jss.2019.73023

Received: January 7, 2019

Accepted: March 12, 2019

Published: March 15, 2019

Copyright $\odot 2019$ by author(s) and Scientific Research Publishing Inc. This work is licensed under the Creative Commons Attribution International License (CC BY 4.0).

http://creativecommons.org/licenses/by/4.0/

(c) (i) Open Access

\begin{abstract}
Krisoker Janala (Farmers Window) is a newly develop app that is used by the agricultural extension agent of Bangladesh to spread information to the farmers. In this regard, the objectives of this study were to assess the effectiveness of Krisoker Janala for disseminating agricultural information and to explore the contributory factors of using Krisoker Janala. Data were collected from 106 Sub Assistant Agriculture Officers (SAAOs) under four upazilas (sub district) of Chuadanga district. A face to face interview followed by structured questionnaire was conducted to collect data from the SAAOs during a period of early June to the end of July, 2018. The result of interview revealed that $64.2 \%$ of the respondents perceived that use of Krisoker Janala is moderately effective while $24.5 \%$ and $11.3 \%$ of them perceived as less and high effective respectively. Multiple regression analysis was applied to identify significant factors and it was found that out of seven factors, three namely extent of ICT use, the information quality of Krisoker Janala and use of Krisoker Janala had significant positive contribution to their perceived effectiveness of Krisoker Janala for disseminating agricultural information. So, the policy makers should consider to these important factors in order to increase the effectiveness of this agro based app as well as for providing better service to the farmers.
\end{abstract}

\section{Keywords}

Effectiveness, Krishoker Janala, Information Dissemination, Bangladesh Agriculture

\section{Introduction}

Bangladesh is an agrarian country and the development of the agriculture sector 
in last two decades is remarkable. In this development process, a momentous role has been played by agricultural extension. A number of Government Organizations (GOs) and Non-Government Organizations (NGOs) provide agricultural extension services to the farmers. Among the services, providing agricultural advisory services to the farmer is a major one. A study of [1] revealed that from extension service provider, $80 \%$ of Bangladeshi farmers typically seek information on pest management and disease prevention. However, due to the existence of communication gap between the farmers and extension agent, sometimes problems are identified in wrong ways and inappropriate suggestions are provided to the farmers. [2] explained that this type of communication noise is caused mainly by the sender i.e., the encoder due to the use of grammar or technical language or jargon that the receiver i.e. the decoder cannot understand. An electronic and device responsive pictorial database of plant's problem can be used to address all these issues effectively that minimizes the communication noises between farmer and extension agent.

The farmers of Bangladesh do not receive up-to-date and timely information on ways to identify and treat plant diseases, and their lack of formal education means they use crude and inaccurate terms to identify with plant diseases. These challenges have been addressed by Krisoker Janala (Farmer's Window), an inexpensive to build and inexpensive to operate, user centric indigenous innovation. Actually, for knowledge management Krisoker Janala is used as an important tool. [3] reported that effective knowledge management is achieved when the right knowledge and information are delivered to the right person at the right time in a user friendly and accessible manner that helps the recipients to perform their jobs efficiently. The outcome of effective knowledge management includes improved productivity and performance of the agricultural sector. To ensure this Krisoker Janala is an effective agricultural extension tool. The initiative is also an effective means of disseminating agricultural information.

"Krisoker Janala" is a mobile-based application. Users can download it in their mobile devices and use locally in offline form without the Internet. More than one thousands (1000) problems of 120 crops are present in this mobile application. Generally field crops, vegetables, fruits and others plants' diseases, pests, nutritional deficiencies alone with their images are present in this system. A farmer can easily identify his/her problem of crops by seeing the images in the system. The app has been proven as a time saving system, because they don't have to go to others [4]. Farmers often seek help from SAAOs (who served as root level extension agent) about their farming problems. However, it becomes often difficult to clearly identify any disease or problem without knowing proper signs and symptoms. This mobile application therefore assists users to identify the problem or disease by searching the images and symptoms [5]. Since quick identification of disease is vital for crop cultivation, this application could work as an important weapon for the farmers.

This study attempts to evaluate one of the agricultural advisory system projects "Krisoker Janala", (A “Digital Completion and Standardization of Plants' 
Problem Identification System (DPPIS))" which is a joint venture project of the Department of Agricultural Extension (DAE), Access-to-Information (A2I) project, UNDP, USAID and Bangladesh Government [6]. Many researchers have been done with ICT. But research with effectiveness of Krisoker Janala for disseminating agricultural information has not done ever. In this context, there is a need to conduct a study entitled effectiveness of Krisoker Janala for disseminating agricultural information. The objectives of the study are; to describe the selected characteristics of the SAAO's; to assess the effectiveness of Krisoker Janala for disseminating agricultural information as perceived by the SAAOs and to explore the contribution of the SAAOs characteristics on the effectiveness of Krishoker Janala.

\section{Methodology}

\subsection{Study Area, Population and Sampling}

The study was conducted at Chuadangasadar, Alamdanga, Damurhuda and Jinanagar Upazilla (sub district) under Chuadanga district of Bangladesh where easy communication as well as easy contact with the SAAOs who use Krisoker Janala for disseminating agricultural information. Since the selected case of ICT-based advisory system "Krisoker Janala" was first time piloted in those upazilas. As a locale to the proposed study, four Upazilas of Chuadanga District were selected purposively.

The SAAOs of the selected upazilas were the population of the study. Four separated lists of the selected SAAOs were prepared with the help of Upazila Agricultural Officers of four Upazila in Chuadanga district. The total numbers of SAAOs in these four Upazilas were 106 which are considered as population of the study. The whole populations were selected as sample of the study [7]. The distribution of population, sample and location is shown in Table 1.

\subsection{Selection and Measurement of Variables}

Ina descriptive social research, selection and measurement of the variable is a momentous task [9]. An organized research usually contains at least two important variables, viz. an independent and a dependent variable. Considering study nature, the location, time and other logistic support, we selected seven (7) characteristics of the SAAOs as the independent variables for the study. These are SAAOs age, ICT ownership, extent of ICT use for work, use of Krisoker Janala, the quality of information of Krisoker Janala as perceived by the SAAOs, problem faced in using Krisoker Janala and job experience. On the other hand, effectiveness of Krisoker Janala for disseminating agricultural information was the dependent variable of the study.

Ages of the respondent were measured in terms of actual years from their birth to the time of interview. ICT ownership of the respondents was measured on the basis of nature of access of four selected ICT devices or communication media. Extent of use of ICTs for agriculture was captured by four items. Use of 
Table 1. Distribution of population of SAAOs of Chuadnga district.

\begin{tabular}{cccc}
\hline Name of the district & Name of the upazila & Total SAAOs (population) & Sample \\
\hline \multirow{3}{*}{ Chuadanga } & Chuadangasadar & 22 & 22 \\
& Alamdanga & 40 & 40 \\
& Jibonnagar & 22 & 22 \\
Total & Damorhuda & 22 & 22 \\
& 4 & 106 & 106 \\
\hline
\end{tabular}

Source: [8].

Krisoker Janala was measured by the number of times used in last one month. The quality of information of Krisoker Janala as perceived by the SAAOs was measured by three-point modified Likert Scale. Problem faced in using Krisoker Janala was measured by using a four point rating scale. A list of 5 probable problems that SAAOs could face in different aspects were listed and asked to indicate the extent of their problem confrontation. Job experience was operationalized by counting the length of years a respondent actively involved in job.

Effectiveness of Krisoker Janala was the dependent variable of this study. It was measured on the basis of opinion provided by the respondents on 9 statements regarding the extent of effectiveness of Krisoker Janala. The respondents were requested to give their responses to those 9 statements. Four point scales namely "highly effective", "effective", "low effective", and "not at all effective" were used to measure the extent of effectiveness and a score of 3, 2, 1 and 0 was given for the responses. The effectiveness score of a respondent was obtained by adding the scores from all selected items and it could range from 0 to 27, where " 0 " indicates no effectiveness of Krisoker Janala for disseminating agricultural information and "27" indicates highest effectiveness.

\subsection{Data Collection and Analysis}

In order to collect reliable and valid Information from the SAAOs, an interview schedule was prepared carefully keeping the objectives of the study in mind. The interview schedule contained both open and closed form questions. Pre-test with the draft interview schedule with 5 SAAOs was accomplished. Based on the pre-test result, necessary corrections, modifications, addition, alternation were made in the interview schedule and then finalized it. Data was collected by face to face interviewing with the respondents. After collection of data they were processed before analysis.

Descriptive statistical measures, including range, mean, average, and standard deviation was used to describe SAAOs characteristics. Multiple regression analysis was run to determine the contribution of the selected factors to effectiveness of Krisoker Janala for disseminating agricultural information.

The model used for this analysis can be explained as follows:

$$
Y_{i}=a+b_{1} x_{1}+b_{2} x_{2}+b_{3} x_{3}+b_{4} x_{4}+b_{5} x_{5}+b_{6} x_{6}+b_{7} x_{7}+e
$$


where $Y_{i}$ is the effectiveness of Krisoker Janala; $\mathrm{x}_{1}$ is their age; $\mathrm{x}_{2}$ is the ICT ownership; $x_{3}$ is the extent of use of ICT; $x_{4}$ is the use of Krisoker Janala; $x_{5}$ is the quality of information of Krisoker Janala; $x_{6}$ is the SAAOs problem faced in using Krisoker Janala; $\mathrm{x}_{7}$ is job experience. $\mathrm{b}_{1}, \mathrm{~b}_{2}, \mathrm{~b}_{3}, \mathrm{~b}_{4}, \mathrm{~b}_{5}, \mathrm{~b}_{6}$ and $\mathrm{b}_{7}$ are regression coefficients of the corresponding independent variables and " $\mathrm{e}$ " is random error, which is normally and independently distributed with zero (0) mean and constant variance.

\section{Result and Discussion}

\subsection{Selected Characteristics of the SAAOs}

The salient features of the selected characteristics of the respondents are shown in Table 2. The observed age of the respondents ranged from 25 to 58 years. It can be said from the mean value that majority of the respondents are middle aged, moderate user of Krisoker Janala and use of ICT. Though a varying degree but all of them had ICT tools and they faced problems in using Krisoker Janala. Majority of them had long job experience and they perceived that the quality of information of Krisoker Janala was fair.

\subsection{Effectiveness of Krisoker Janala for Disseminating Agricultural Information}

The observed effectiveness of Krisoker Janala scores of the respondents ranged from 15 to 24 against the possible range of $0-27$. The average perceived effectiveness was 21.01 and the standard deviation was 2.14 . The respondents were classified into three categories based on their perceived effectiveness of Krisoker Janala which is shown in Table 3.

Data in Table 3 reveals that majority (64.2 percent) of the respondents reported that "Krisoker Janala" was moderately effective while 11.3 percent and 24.5 percent of them perceived it as high and less effective respectively as a medium for disseminating agricultural information. A few of the SAAOs mentioned that the app is high effective which indicates there is a need to take initiative to increase the effectiveness of Krishoker Janala.

\subsection{The Contribution of the Selected Characteristics of the Respondents to their Perceived Effectiveness of Krisoker Janala for Disseminating of Agricultural Information}

The contribution of the selected characteristics of the SAAOs to their perception on the effectiveness of Krisoker Janala for disseminating of agricultural information has been shown in Table 4. The table shows that out of seven characteristics only three namely extent of ICT use, use of Krisoker Janala and quality of information of Krisoker Janala had significant contribution to the effectiveness of Krisoker Janala. The remaining characteristics such as age, ICT ownership, problem faced in using Krisoker Janala, job experience have no significant contribution. 
Table 2. Salient features of the selected characteristics of the respondents.

\begin{tabular}{cccccc}
\hline Characteristics & $\begin{array}{c}\text { Unit of } \\
\text { measurement }\end{array}$ & Possible range & $\begin{array}{c}\text { Observed } \\
\text { range }\end{array}$ & Mean & S D \\
\hline Age & Years & unknown & $25-58$ & 38.52 & 7.10 \\
ICT ownership & Scores & $0-8$ & $5-8$ & 6.29 & 0.894 \\
$\begin{array}{c}\text { Extent of ICT use } \\
\text { Use of Krisoker Janala }\end{array}$ & Scores & $0-16$ & $6-14$ & 10.68 & 2.15 \\
$\begin{array}{c}\text { The quality of information } \\
\text { of Krisoker Janala }\end{array}$ & Scores & unknown & $4-21$ & 11.52 & 3.79 \\
$\begin{array}{c}\text { Problem faced in using } \\
\text { Krisoker Janala }\end{array}$ & Scores & $3-9$ & $5-9$ & 6.20 & 0.90 \\
$\begin{array}{c}\text { Job experience } \\
\text { Yobres }\end{array}$ & Years & unknown & $2-34$ & 16.21 & 5.88 \\
\hline
\end{tabular}

Table 3. Distribution of the respondents according to their perceived effectiveness of Krisoker Janala.

\begin{tabular}{ccccc}
\hline \multirow{2}{*}{ Categories } & \multicolumn{2}{c}{ Respondents SAAO } & Mean & S D \\
\cline { 2 - 3 } & Number & Percent & & \\
\hline Less effective (up to 19) & 26 & 24.5 & 21.01 & 2.14 \\
Medium effective (20 - 23) & 68 & 64.2 & & \\
High effective (above 23) & 12 & 11.3 & \\
Total & 106 & 100 & \\
\hline
\end{tabular}

Table 4. Multiple regression coefficients of the contributing variables related to effectiveness of Krisoker Janala for disseminating of agricultural information.

\begin{tabular}{|c|c|c|c|c|c|c|}
\hline Dependent variable & $\begin{array}{c}\text { Independent Variable } \\
\text { (Selected characteristics of } \\
\text { the SAAOs) }\end{array}$ & $\beta$ & $\mathrm{P}$ & $\mathrm{R}^{2}$ & $\begin{array}{l}\text { Adj. } \\
\mathrm{R}^{2}\end{array}$ & $\mathrm{~F}$ \\
\hline \multirow{7}{*}{$\begin{array}{l}\text { Effectiveness of } \\
\text { Krisoker Janala } \\
\text { for Disseminating } \\
\text { of Agricultural } \\
\text { Information }\end{array}$} & Age & 0.039 & 0.813 & \multirow{7}{*}{0.432} & \multirow{7}{*}{0.392} & \multirow{7}{*}{$10.65^{\star *}$} \\
\hline & ICT ownership & 0.058 & 0.544 & & & \\
\hline & Extent of ICT use & 0.475 & $0.000^{* *}$ & & & \\
\hline & Use of Krisoker Janala & 0.183 & $0.044^{*}$ & & & \\
\hline & $\begin{array}{l}\text { Quality of information of } \\
\text { Krisoker Janala }\end{array}$ & 0.267 & $0.001^{* *}$ & & & \\
\hline & $\begin{array}{l}\text { Problem faced in using } \\
\text { Krisoker Janala }\end{array}$ & -0.017 & 0.833 & & & \\
\hline & Job experience & 0.189 & 0.259 & & & \\
\hline
\end{tabular}

${ }^{* *}$ Significant at $\mathrm{p}<0.01 ; *$ Significant at $\mathrm{p}<0.05$.

Multiple regression analysis was computed to find out contributing independent variables of effectiveness of Krisoker Janala for disseminating agricultural information. All the variables when considered together, the predictability 
co-efficient $\mathrm{R}^{2}$ was 0.432 . [10] found similar contribution. This means that all variables put together would bring $43.2 \%$ variation of effectiveness of Krisoker Janala for disseminating agricultural information. However, among all variables, extent of ICT use, use of Krisoker Janala, quality of information of Krisoker Janala had positive significant contribution on effectiveness of Krisoker Janala for disseminating agricultural information. The $\mathrm{F}$ value was found significant at $1 \%$ level. Hence, it may be concluded that the selection of analysis was valid.

Data presented in Table 4 revealed that the extent of ICT use had positive and significant contributed (significant at $1 \%$ level, $p<0.000$ ) on effectiveness of Krisoker Janala for disseminating of agricultural information. From the finding it can be said that higher the use of ICT, higher the effectiveness of Krisoker Janala. Use of ICT increases skill of the users which might have influence to make effective use of any app like Krisoker Janala. The finding is supported by [11] [12] and [13].

It was revealed from analysis that use of Krisoker Janala was positive and significantly contributed (significant $5 \%$ level, $\mathrm{p}<0.05$ ) on effectiveness of Krisoker Janala for disseminating agricultural information. [6] [14] [15] found similar findings. So, it can be said that more use of Krisoker Janala increased the effectiveness of the app. Frequent use of any app make flexible and comfortable to the users with that app. This may be probable reason behind the result.

From the analysis, it is also indicated that the quality of information of Krisoker Janala was positive and significantly contributed (significant at $1 \%$ level, $p$ $<0.01$ ) on effectiveness of Krisoker Janala. From the analysis it means that if the SAAOs think that the quality of information of Krisoker Janalais good enough then they will use more the app. Favorable perception influence people to use technology. [16] revealed that farmers favorable perception influence them to use adaptation strategy which is similar to the present study.

\section{Conclusion and Recommendation}

There is no scope to deny that development of ICT based tool is urgent for agricultural development. Krisoker Janala is an app that is used by the agricultural extension agent to serve the farmers. The present study found that only few farmers (11.3\%) think that the effectiveness of Krisoker Janala is high. The rest opined that low to moderate effectiveness which indicates steps should be taken to increase the effectiveness of this agro based app. The study also found that effectiveness of Krisoker Janala is influenced by the SAAOs' use of other ICT tools, extent of use of this app and perception regarding quality of information bearing this app. In this regard, the Department of Agricultural Extension (DAE) and Ministry of Agriculture should take steps to provide more ICT based tools to the SAAO so that they can increase their capacity to use ICT based tool like Krisoker Janala. Moreover, the database use in the app should update time to time and monitor the quality of information using the app for increasing the acceptance level of the app. 


\section{Conflicts of Interest}

The authors declare no conflicts of interest regarding the publication of this paper.

\section{References}

[1] Katalyst (2011) Media Behavior of the Poor. Katalyst, Dhaka.

[2] Rothwell, D.J. (2004) In the Company of Others: An Introduction to Communication. McGraw Hill, New York.

[3] Islam, F. (2010) Institutionalization of Agricultural Knowledge Management System for Digital Marginalized Rural Farming Community, ISDA. Montpellier, France.

[4] Campenhout, B.V. (2017) There Is an App for That? The Impact of Community Knowledge Workers in Uganda. Information, Communication and Society, 20, 530-550. https://doi.org/10.1080/1369118X.2016.1200644

[5] Aker, J.C. and Mbiti, I.M. (2010) Mobile Phones and Economic Development in Africa. Journal of Economic Perspectives, 24, 207-232. https://doi.org/10.1257/jep.24.3.207

[6] Sabbir, M. (2016) Effectiveness of Krishoker Janala for Strengthening Agricultural Advisory System. MS Thesis, Department of Agricultural Extension and Information System, Sher-e-Bangla Agricultural University, Dhaka.

[7] Arafat, Y. (2017) Adoption of Broiler Production Practices by the Farmers. MS Thesis, Department of Agricultural Extension and Information System, Sher-e-Bangla Agricultural University, Dhaka, Bangladesh.

[8] District Agriculture Office (DAO) (2017) Department of Agricultural Extension, Chuadanga.

[9] Kabir, M.H. (2006) Adoption of Selected T. Aman Production Technologies by the Farmers. MS Thesis, Department of Agricultural Extension and Information System, Sher-e-Bangla Agricultural University, Dhaka, Bangladesh.

[10] Kabir, M.H., Azad, M.J., Rahman, M.M., Alam, M.M. and Haque, M.Z. (2017) Potato Farmer's Postharvest Problems in Joypurhat District of Bangladesh. J. Expt. Biosci, 8, 23-28.

[11] Zhang, Y., Wang, L. and Daun, Y. (2016) Agricultural Information Dissemination Using ICTs: A Review and Analysis of Information Dissemination Models in China. Information Processing in Agriculture, 3, 17-29. https://doi.org/10.1016/j.inpa.2015.11.002

[12] Kargin, B. and Basoglu, N. (2007) Factors Affecting the Adoption of Mobile Services. PICMET Proceedings, Portland, USA.

[13] Kwon, H.S. and Chidambaram, L.A. (2000) Test of the Technology Acceptance Model, the Case of Cellular Telephone Adoption. Proceedings of the 33rd Hawaii International Conference on System Sciences, Maui, HI, 7-7 January 2000. https://doi.org/10.1109/HICSS.2000.926607

[14] Davis, F.D. (1989) Perceived Usefulness, Perceived Ease of Use, and User Acceptance of Information Technology. MIS Quarterly, 13, 319-340. https://doi.org/10.2307/249008

[15] Renaud, K. and Biljon, J.V. (2008) A Qualitative Study of the Applicability of Technology, Acceptance Models to Senior Mobile Phone Users, Advances in Conceptual Modeling: Challenges and Opportunities. Lecture Notes in Computer Science 
(SAICSIT), Vol. 5232, Springer, Berlin/Heidelberg.

[16] Kabir, M.H., Islam, M.S., Ali, M.S. and Abdullah, M.M. (2018) Farmer's Perception towards Harmful Effects of Climate Change on Agriculture. Asian Journal of Agricultural Extension, Economics and Sociology, 27, 1-8.

https://doi.org/10.9734/AJAEES/2018/43006 